\title{
Guided Inquiry in Sophomore Organic Lecture: Deducing Mechanisms by Reaction Mapping
}

\section{COMMUNICATION}

Douglass F. Taber*

Department of Chemistry and Biochemistry, University of Delaware, Newark, DE 19716

*taberdf@udel.edu

\begin{abstract}
:
Arrow-pushing mechanisms can be understood more readily if the changes from starting material to product are systematically charted. This can be done by labeling the relevant atoms in the starting material and in the product, then making lists of the bonds to be broken and the bonds to be formed.
\end{abstract}

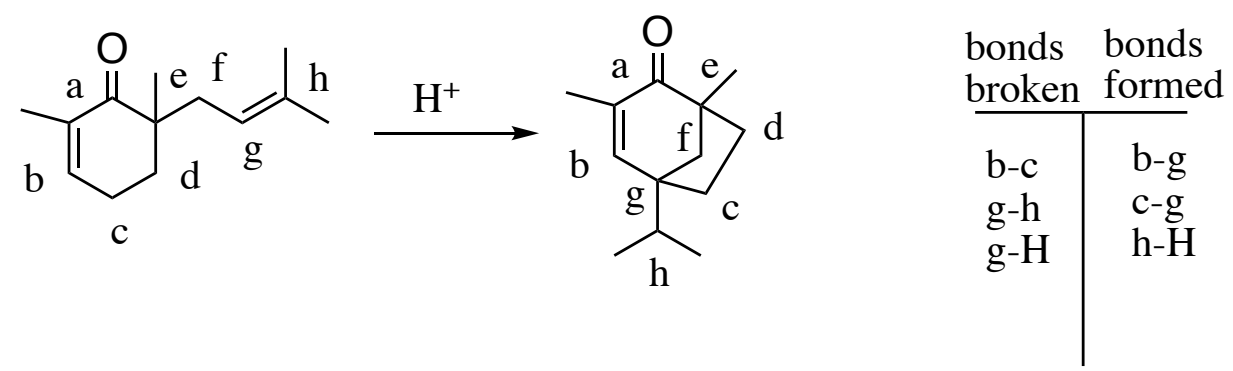

Key Words: Second-Year Undergraduate, Organic Chemistry, Inquiry Based/Discovery Learning, Mechanisms of Reactions, Covalent Bonding 


\section{Guided Inquiry in Sophomore Organic Lecture: Deducing Mechanisms by Reaction Mapping}

One objective of sophomore organic chemistry is to enable each student to construct their understanding of organic reaction mechanisms. The efficacy of the guided inquiry/problembased learning approach to instruction in organic chemistry has been well documented, particularly in the laboratory course. ${ }^{1-9}$ Incorporating guided inquiry into the sophomore organic lecture course ${ }^{10-12}$ has been more challenging, especially early in the course.

One hundred years ago, Robert Robinson introduced ${ }^{13}$ the use of arrow-pushing to help rationalize electron flow in an organic reaction. Nevertheless, it has been observed ${ }^{14}$ that even some beginning $\mathrm{Ph} . \mathrm{D}$. students in organic chemistry cannot competently produce coherent arrow-pushing explanations. Much work has gone into devising strategies to better teach that proficiency. ${ }^{15-21}$

We have incorporated guided inquiry/problem-based learning from very early in the sophomore organic lecture by teaching the students to break down the solving of arrow-pushing mechanisms into six discrete steps. The three examples here are drawn from exams in the first semester of a sophomore organic course.

1. What is sort of mechanism is this? Initially, the students had three options: acid catalyzed, nucleophilic anionic, and free radical. Later in the year, sigmatropic rearrangements (e.g. DielsAlder) were added. 
2. Label the relevant atoms in the starting material, then deduce where each of those atoms is in the product.

3. Make a list of bonds broken and a list of bonds formed. This becomes a series of tasks to be accomplished.

4. Decide how you are going to begin. For acid-catalyzed mechanisms, this will be protonation to activate for bond cleavage. For nucleophilic anionic machanisms, what is the initial nucleophile? For free radical reactions, this will be generation of the initial radical.

5. Decide how you are going to end. For acid catalyzed mechanisms, this will usually be loss of a proton. For nucleophilic anionic mechanisms, it is often protonation, perhaps on work up. For free radical reactions, the last step is usually $\mathrm{H}$ atom transfer.

6. Begin the mechanism following this guidance, using curved arrows to show electron flow, bond breaking and bond formation. At the same time, work in reverse, beginning with the product and working backwards.

To illustrate, consider the transformation (Fig. 1) of $\mathbf{1}$ into 2. For ease of grading, it is easiest to label the starting material before presenting the problem to the student.

1. This is an acid-catalyzed reaction. 

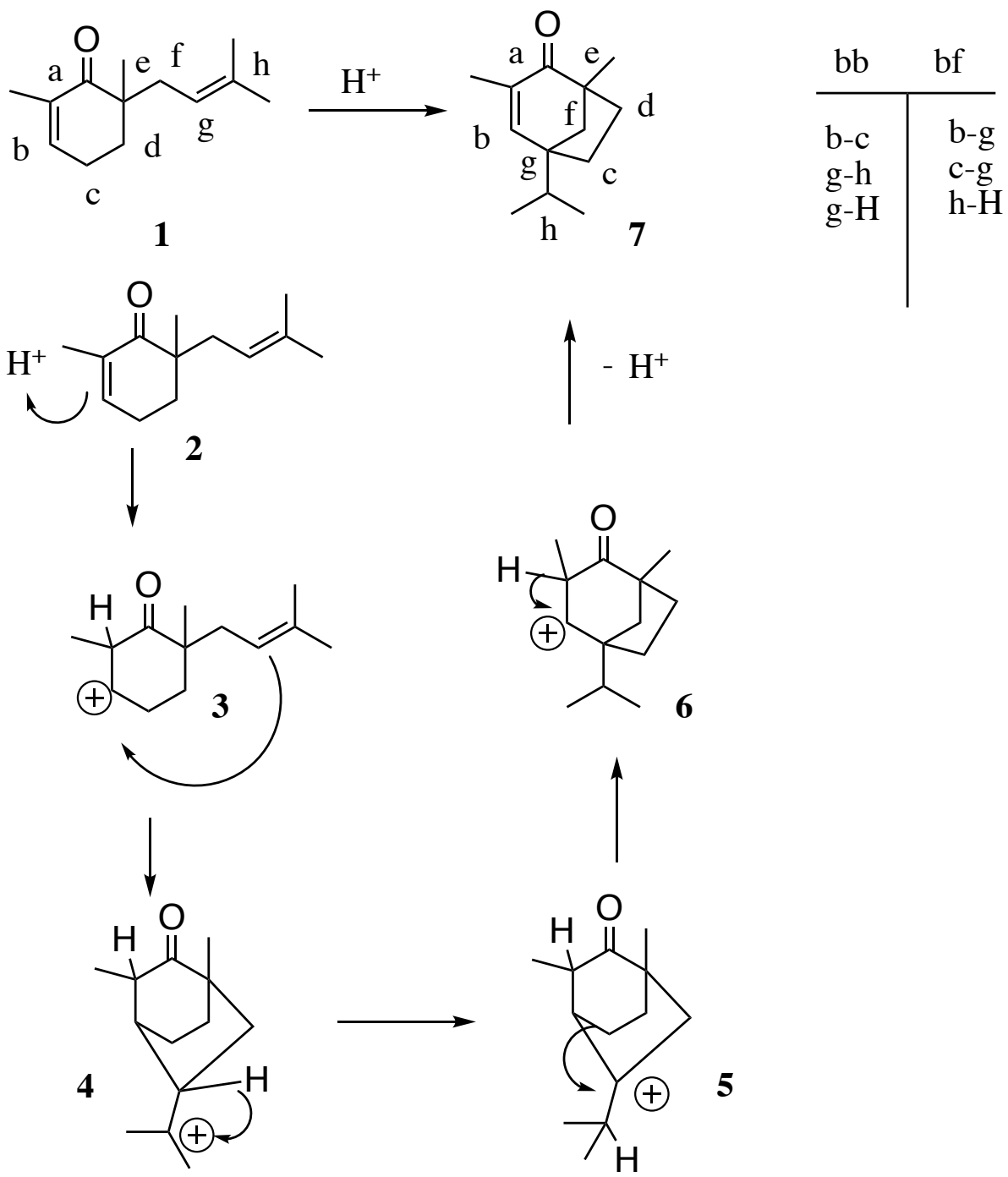

Fig. 1: Acid-catalyzed Reaction

2. As the problem is presented, the starting material is labeled. The first challenge is to accurately label the relevant heavy atoms in the product

3. Make a list of bonds broken and a list of bonds formed. This becomes a series of tasks to be accomplished. 
4. For acid-catalyzed mechanisms, the first step is to protonate to activate for bond cleavage.

5. Decide how you are going to end. For acid catalyzed mechanisms, this will usually be loss of a proton.

6. Begin the mechanism following this guidance, using curved arrows to show electron flow, bond breaking and bond formation. At the same time, work in reverse, beginning with the product and working backwards. This leads to the solution shown.

This process works as well with a bromination (Fig. 2).

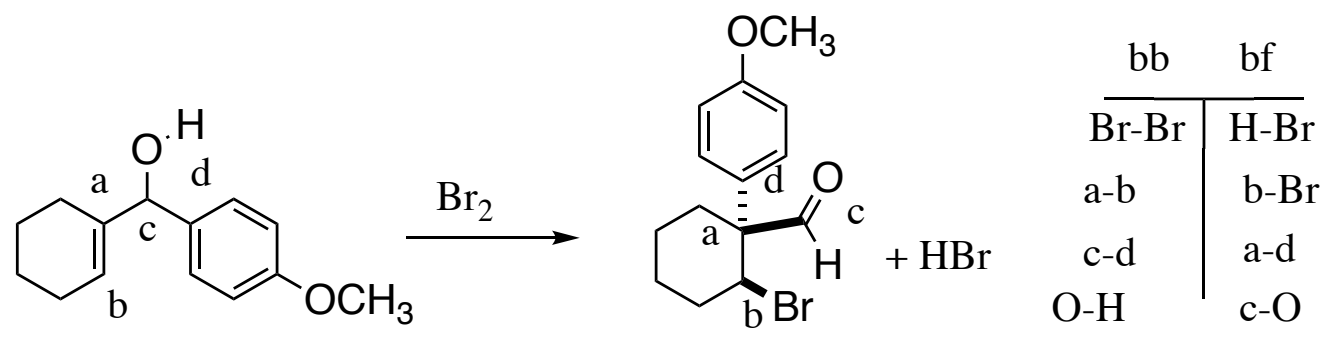

8

9

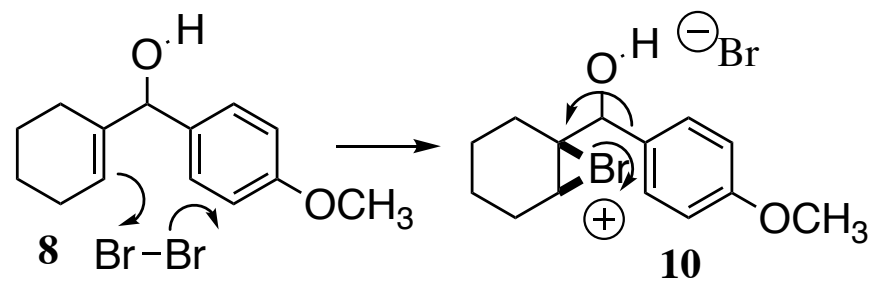

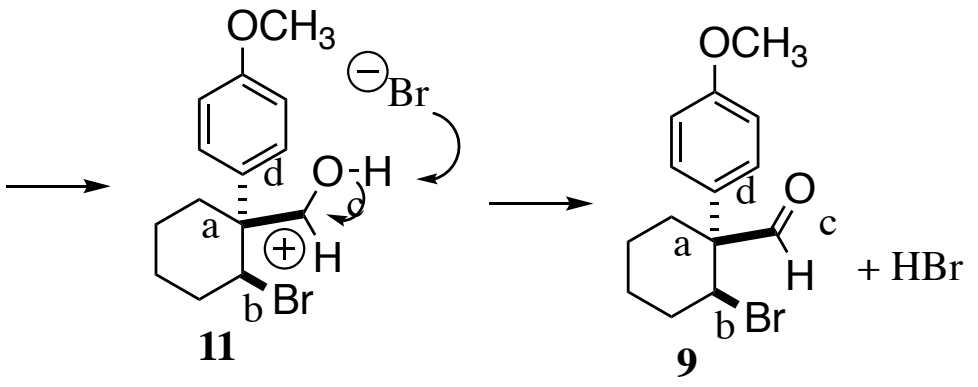


1. This is a bromination.

2. The reaction begins with bromination of the alkene.

3. The intermediate bromonium ion rearranges to give the more stable carbocation.

4. The reaction concludes with loss of $\mathrm{H}^{+}$.

Free radical reactions are often introduced early in the sophomore organic lecture, alkane halogenation, then not used further. Free radical reduction of a halide with $\mathrm{Bu}_{3} \mathrm{SnH}$ offers the opportunity to chart free radical reactions over several steps (Fig. 3). Note that for free radical reactions, single-headed arrows are used.

1. The first step in all such reactions is the abstraction of the $\mathrm{H}$ atom from the $\mathrm{Sn}-\mathrm{H}$ bond, to form the tin radical. The students were taught about the use of free radical initiators, but for simplicity were told to start free radical reductions as illustrated.

2. The next step in all such reactions is the abstraction of halide from the starting material to give the initial radical, in this case $\mathbf{1 4}$. 
3. The last step in all such reactions is $\mathrm{H}$ atom abstraction by the final radical from $\mathrm{Sn}-\mathrm{H}$, to give the final product, in this case 13. It follows, from the list of bonds formed, that the final radical must be 16.
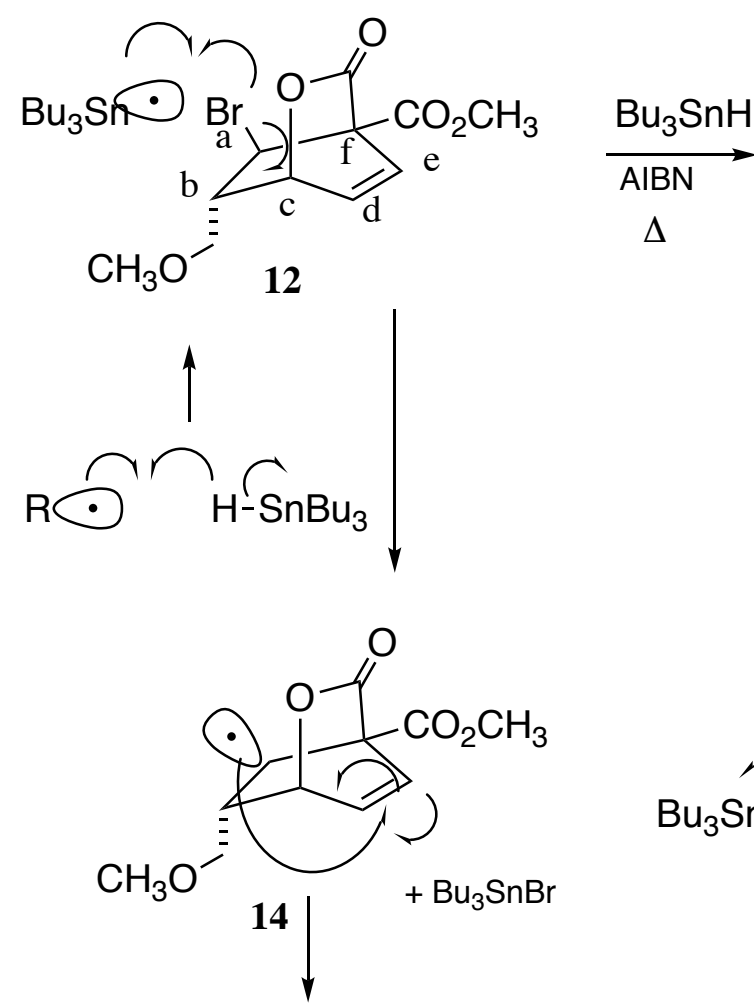

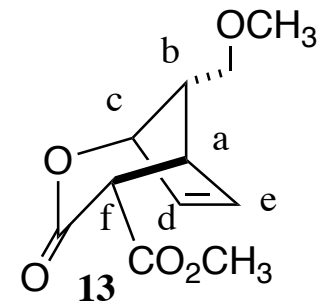

13

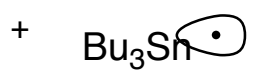

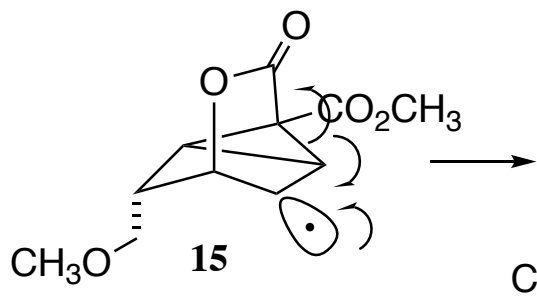
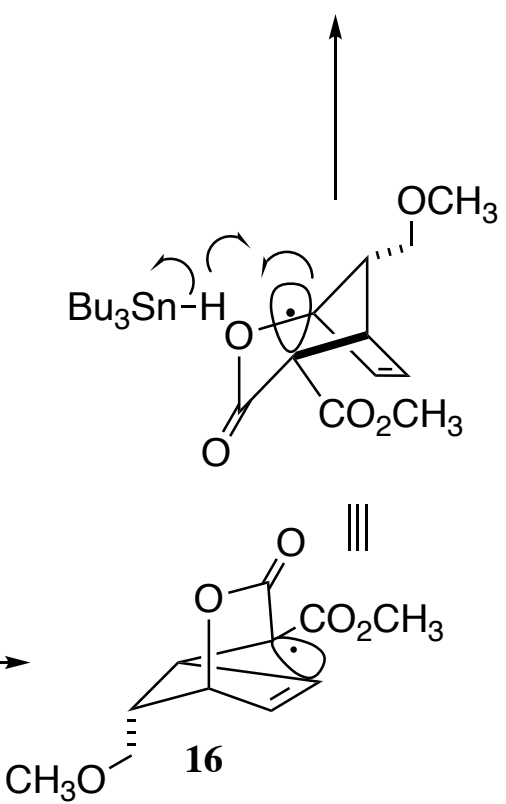

Fig. 3: Free Radical Reduction

4. The challenge, then, is to transform the initial radical into the final radical. From the list of bonds broken and bonds formed, "a" is connected to "e". 
5. Again from the list of bonds broken and bonds formed, the e-f bond has to break. That leads to the final radical.

Each of the problems used here was the last problem on the last exam from the first semester of a sophomore organic course. The students had been practicing this approach all through the semester. Over each of those three years, with an enrollment each year of about 120, more than 100 of the students were able to make correct lists of bonds broken and bonds formed.

Conclusion: The approach outlined here formalizes and makes explicit the approach any experienced organic chemist would take toward figuring out the mechanism of an organic transformation. Teaching the approach in this stepwise fashion makes it particularly easy for the student to grasp, and practice. Many additional problems with their answers, over a wide range of difficulty, are available at http://www1.udel.edu/chem/valhalla/C331.html and http://www1.udel.edu/chem/valhalla/C332.html.

\section{Associated Content}

None

\section{Author Information}

Corresponding Author

*Email: taberdf@udel.edu

\section{Notes}

The author declares no competing financial interest. 


\section{Literature Cited}

(1) Gaddis, B. A.; Schoffstall, A. M. Incorporating Guided-Inquiry into the Organic Chemistry Laboratory. J. Chem. Educ. 2007, 84 (5), 848-851.

(2) Mohrig, J. R.; Hammond, C. N.; Colby, D. A. On the Successful Use of Inquiry-Driven Experiments in the Organic Chemistry Laboratory. J. Chem. Educ. 2007, 84 (6), 992-998.

(3) Bernard, E.; Britz-McKibbin, P.; Gernigon, N. Resveratrol Photoisomerization: An Integrative Guided-Inquiry Experiment. J. Chem. Educ. 2007, 84 (7), 1159-1161.

(4) Schepmann, H. G.; Mynderse, M. Ring-Closing Metathesis: An Advanced Guided-Inquiry Experiment for the Organic Laboratory. J. Chem. Educ. 2010, 87 (7) 721-723.

(5) Wheeler, L. B.; Clark, C. P.; Grisham, C. M. Transforming a Traditional Laboratory to an Inquiry-Based Course: Importance of Training TAs when Redesigning a Curriculum. J. Chem. Educ. 2017, 94 (8), 1019-1026.

(6) Latimer, D. R.; Ata, A.; Forfar, C. P.; Kadhim, M.; McElrea, A.; Sales, R. Overcoming the Hurdle from Undergraduate Lab to Research Lab: A Guided-Inquiry Structural Characterization of a Complex Mixture in the Upper-Division Undergraduate Organic Lab. J. Chem. Educ. 2018, 95 (11), 2046-2049.

(7) Balija, A. M.; Morsch, L. A. Inquiry-Based Ir-Spectroscopy Activity Using iSpartan or Spartan for Introductory-Organic-Chemistry Students. J. Chem. Educ. 2019, 96 (5), 970-973.

(8) Nagarajan, S.; Overton, T. Promoting Systems Thinking Using Project- and Problem-Based Learning. J. Chem. Educ. 2019, 96 (12), 2901-2909.

(9) Kovacevic, T.; Skinner, A.; Fisk, J. D.; Fishback, V.; Reed, S. M. A Semester-Long, Organic Chemistry Laboratory Structured around Unknown Analysis and Resynthesis as a Bridge to Guided-Inquiry. J. Chem. Educ. 2020, 97(6), 1633-1636.

(10) Conway, C. J. Effects of Guided Inquiry versus Lecture Instruction on Final Grade Distribution in a One-Semester Organic and Biochemistry Course J. Chem. Educ. 2014, 91 (4), 480-483.

(11) Stowe, R. L.; Cooper, M. M. Arguing from Spectroscopic Evidence. J. Chem. Educ. 2019, 96 (10), 2072-2085.

(12) Agnello, A.; Vanberg, S.; Tonus, C.; Boigelot, B.; Leduc, L.; Damblon, C.; Focant, J.-F. Introducing Molecular Structural Analysis Using a Guided Systematic Approach Combined with an Interactive Multiplatform Web Application. J. Chem. Educ. 2020, 97 (12), 4330-4338.

(13) Kermack, W. O.; Robinson, R. LI. An explanation of the property of induced polarity of atoms and an interpretation of the theory of partial valences on an electronic basis. J. Chem. Soc., Trans. 1922, 121, 427-440. 
(14) Bhattacharyya, G.; Bodner, G.M. "It Gets Me to the Product": How Students Propose Organic Mechanisms. J. Chem.Educ. 2005, 82, 1402-1407.

(15) Chen, J. H.; Baldi, P. Synthesis Explorer: A Chemical Reaction Tutorial System for Organic Synthesis Design and Mechanism Prediction. J. Chem. Educ. 2008, 85, 1699-1703.

(16) Straumanis, A. R.; Ruder, S. M. New Bouncing Curved Arrow Technique for the Depiction of Organic Reaction Mechanisms. J. Chem. Educ. 2009, 86, 1389-1391.

(17) Ruder, S. M.; Straumanis, A. R. A Method for Writing Open-Ended Curved Arrow Notation Questions for Multiple-Choice Exams and Electronic Response Systems. J. Chem. Educ. 2009, 86, 1392-1396.

(18) Grove, N. P.; Cooper, M. M.; Rush, K. M. Decorating with Arrows: Toward the Development of Representational Competence in Organic Chemistry. J. Chem. Educ. 2012, 89, 844-849. (e) Grove, N. P.; Cooper, M. M.; Cox, E. L. Does Mechanistic Thinking Improve Student Success in Organic Chemistry? J. Chem. Educ. 2012, 89, 850-853.

(19) Bhattacharyya, G. From Source to Sink: Mechanistic Reasoning Using the Electron-Pushing Formalism. J. Chem. Educ. 2013, 90, 1282-1289.

(20) Crandell, O. M.; Kouyoumdijian, H.; Underwood, S. M.; Cooper, M. M. Reasoning about Reactions in Organic Chemistry: Starting It in General Chemistry. J. Chem. Educ. 2019, 96, 213-226.

(21) Crandell, O. M.; Lockhart, M. A.; Cooper, M. M. Arrows on the Page Are Not a Good Gauge: Evidence for the Importance of Causal Mechanistic Explanations about Nucleophilic Substitution in Organic Chemistry. J. Chem. Educ. 2020, 97, 313-327.

TOC Graphic

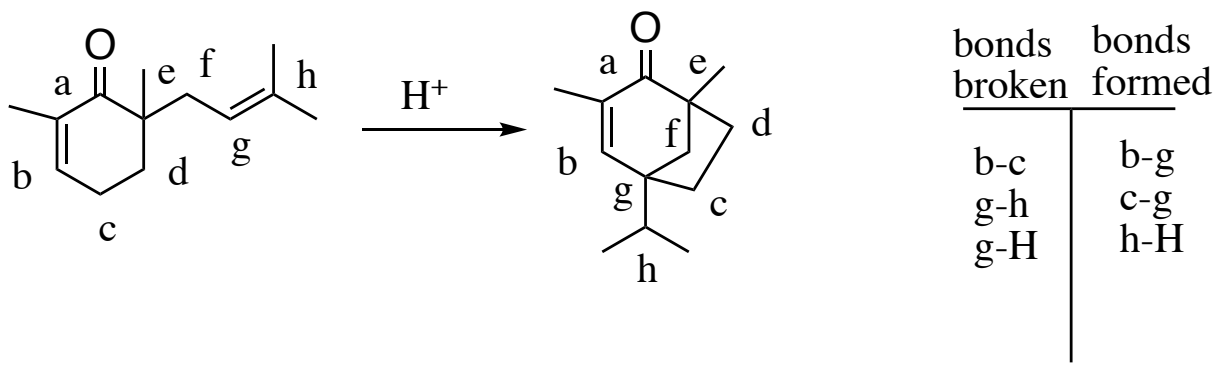

